\title{
Crimean-Congo hemorrhagic fever: epidemiological trends and controversies in treatment
}

\author{
Helena C Maltezou ${ }^{1 *}$ and Anna Papa ${ }^{2}$
}

\begin{abstract}
Crimean-Congo hemorrhagic fever (CCHF) virus has the widest geographic range of all tick-borne viruses and is endemic in more than 30 countries in Eurasia and Africa. Over the past decade, new foci have emerged or re-emerged in the Balkans and neighboring areas. Here we discuss the factors influencing CCHF incidence and focus on the main issue of the use of ribavirin for treating this infection. Given the dynamics of CCHF emergence in the past decade, development of new anti-viral drugs and a vaccine is urgently needed to treat and prevent this acute, life-threatening disease.
\end{abstract}

\section{Background}

Crimean-Congo hemorrhagic fever (CCHF) is an acute, highly-contagious and life-threatening disease caused by a nairovirus of the Bunyaviridae family [1-3]. CCHF was probably described by a physician in Tajikistan in 1100 AD in a patient with hemorrhagic manifestations [2]. In recent times, the disease was first recognized during an outbreak in Crimea in 1944, however, later it became evident that the causative agent was identical to a virus isolated from a patient in Congo in 1956, and the name CCHF was adopted [4]. CCHF virus (CCHFV) circulates in nature in a tick-vertebrate-tick cycle, mainly among cattle, sheep, goats, and hares. The infection is transmitted to humans primarily by ticks of the genus Hyalomma, but also through direct contact with blood or tissues of viremic patients or animals [1,2]. Typical CCHF progresses rapidly with high fever, malaise, severe headache, and gastrointestinal symptoms. CCHF is confirmed either by detection of specific immunoglobulin $M$ antibodies or a four-fold increase of immunoglobulin $\mathrm{G}$ titers using enzyme-linked immunoassays, indirect immunofluorescent assays, or

\footnotetext{
* Correspondence: helen-maltezou@ath.forthnet.gr

'Department for Interventions in Health-Care Facilities, Hellenic Center for Disease Control and Prevention, 3-5 Agrafon Street, Athens, 15123 Greece Full list of author information is available at the end of the article
}

through reverse transcriptase-polymerase chain reaction and microarray techniques $[1,5,6]$. Prominent hemorrhages may occur at a late stage of disease, with case fatality rates ranging from $5 \%$ to $50 \%$. CCHF is a disease of immediate notification to public health authorities because of the potential of nosocomial outbreaks [7-10] and use in bioterrorism [11].

CCHFV has the widest geographic range among all tickborne viruses, being endemic in more than 30 countries in Eurasia and Africa [1,5]. CCHF activity has increased over the past decade and new foci have emerged in several Balkan countries, as well as in neighboring areas (Figure 1) [5,8,12-15]. In a serosurvey conducted in Northeastern Greece after the first human case occurred in June 2008, seroprevalence rates up to $5 \%$ were found in well-confined areas compared with $0 \%$ found in the same areas 20 years ago [16], suggesting recent introduction of the virus. After almost three decades, CCHF re-emerged in southwest Russia in 1999, with hundreds of cases being reported since then [17]. An essential factor of the CCHF re-emergence in Russia was a rise in the number of Hyalomma marginatum ticks [18]. Enzootic circulation of the CCHFV was documented in Turkey for several decades, however the first human cases occurred in 2002; since then, Turkey has experienced the largest ever recorded CCHF outbreak with more than 4,400 confirmed cases, mainly from rural areas in Northeast Anatolia [19]. At the epicenter of this outbreak, the seroprevalence rate was $12.8 \%$ among high-risk groups [20]. Recently, 26 cases were identified in western Turkey [21], indicating further spread towards the west in this country, which is attributed to the vegetation fragmentation in this area, as well as in Anatolia, in association with increased awareness of this disease following the 2006 campaign [21]. This article discusses factors influencing CCHF incidence and focuses on the main issue at stake: the use of ribavirin for treatment.

\section{Factors influencing CCHF incidence}

As for all vector-borne diseases, environmental factors, climate, and human behaviour are critical determinants 


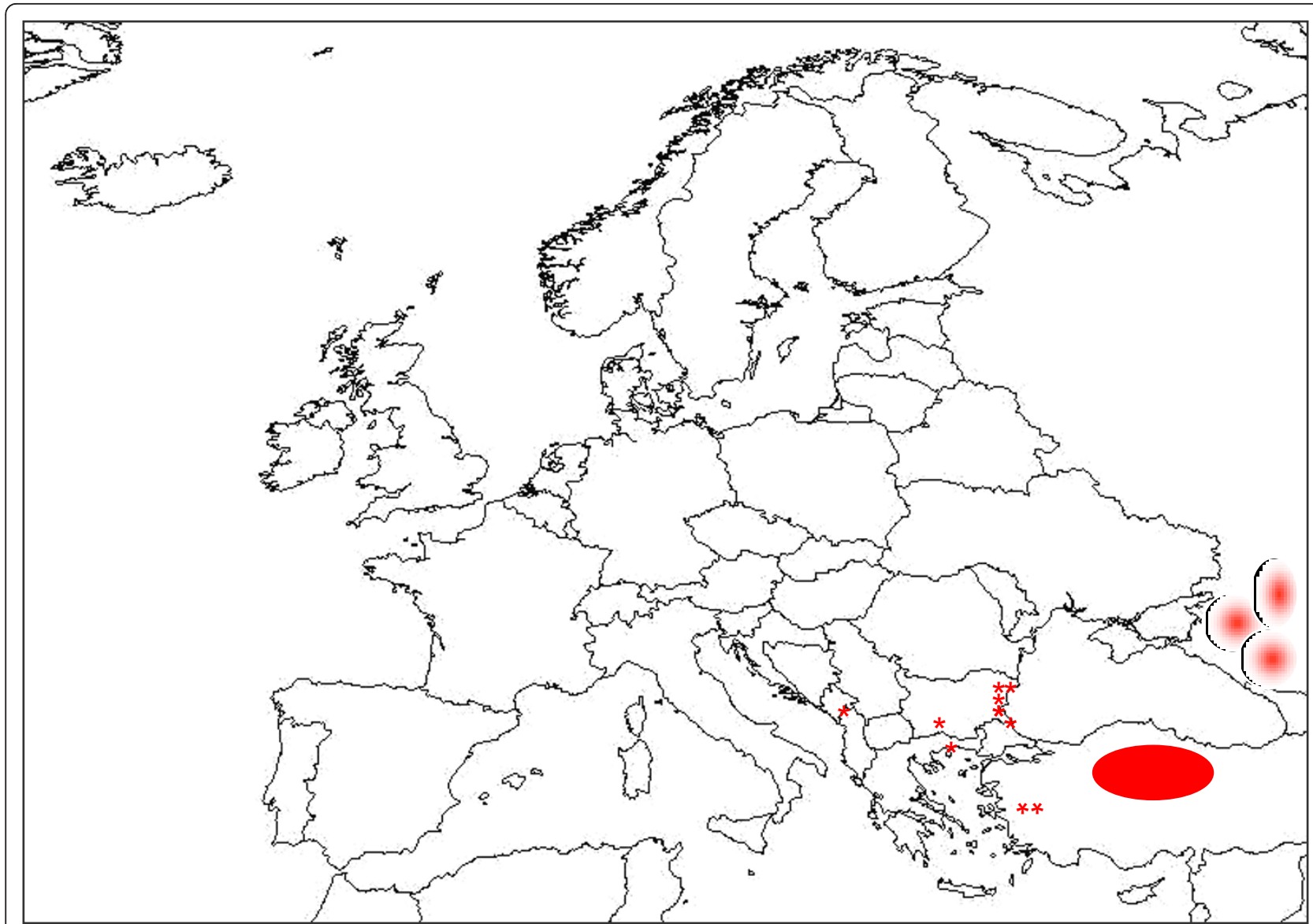

Figure 1 Foci of CCHF emergence or re-emergence in southeast Europe and neighboring countries from 2000. Stars indicate sites of CCHF emergence in southeastern Europe; oval indicates the epicenter of the large CCHF epidemic in Northeastern Anatolia, Turkey; and circles indicate the site of CCHF re-emergence in Southwestern Russia (Data from References 12 and 17). The Figure was created based on a map outline available at: http://geography.about.com/library/blank/blxeurope.htm. Abbreviations: CCHF, Crimean-Congo hemorrhagic fever.

for the establishment and maintenance of CCHF endemicity within an area. However, although explanations about CCHF emergence or re-emergence have been formulated [5,17,22-24], the contribution of each of these factors has not been quantified so far.

Humans may modify the risk of CCHFV transmission through changes in land use, recreational activities, and livestock movement [5], and increasing awareness may also impact the incidence of CCHF [21], whereas limitations in diagnostic capacities and surveillance may hamper the estimation of CCHF burden in several endemic areas [17].

Hyalomma ticks favor dry climates and arid-type vegetation, and are abundant in European countries bordering the Mediterranean Sea, along with numerous animals which may act as CCHFV hosts [12]. However, their established presence does not ensure CCHF expansion to these areas per se. Besides most Balkan countries, which are well-known to be endemic for the presence of CCHF for several decades, serologic evidence of CCHF is scantily available elsewhere in Europe [12,25,26]. Introduction of CCHFV to a non-endemic area could happen either through legal or illegal trade of infected animals or animals infested with infected ticks or through geographic expansion of infected Hyalomma ticks from CCHF-endemic to CCHF-naive areas $[27,28]$.

A model investigating the impact of several climate scenarios on ticks, has found that a rise in temperature and decrease in rainfall in the Mediterranean region could result in a sharp rise of the distribution of suitable habitat for Hyalomma ticks northwards, with the highest impact at the boundaries of their current range [29]. CCHFV infected animals only experience viremia for a few days, which is likely an intrinsic limit for the establishment of successive transmission cycles after their importation, beyond the onset of a localized outbreak [12]. CCHFV seroprevalence rates among animals are good predictors of human risk for infection [14]. Given the dynamics of CCHF over the past decade, further studies on ticks and animals will allow the detection of presumed unaffected 
foci with suitable biotic or abiotic conditions for CCHF emergence [22,23], with the highest risk in neighboring areas to those with established endemicity.

\section{Control strategies}

Given that the control of ticks is an unrealistic goal [30], strategies should focus on enhancing surveillance using standardized case definitions [31], and increasing laboratory capacity within already endemic areas and areas at risk for CCHF expansion [17]. The general population and health-care workers should be aware of prophylactic measures and modify their risk for infection.

An inactivated suckling mouse brain vaccine was developed in the former Soviet Union in the late 1960's with no adverse effects recorded on the limited number of volunteers [30]. Data from approximately 2,000 healthy persons vaccinated in 1970 indicated that neutralizing CCHFV antibodies developed 1 to 4 weeks after the third shot, but titers decreased 3 to 6 months later [30]. The vaccine has been used for high risk groups in Bulgaria since 1974. Although surveillance data suggest a four-fold reduction in the number of notified CCHF cases in Bulgaria after the introduction of vaccination, data regarding vaccine efficacy have not been published [30]. Recently, the CCHFV strain which is used for vaccine preparation was genetically characterized, providing the basis for further studies [32]. Overall, there are concerns about using mouse brain vaccines because of possible autoimmune responses. CCHF is mainly confined to poor resource countries, and research has been extremely slow. A humanized vaccine against CCHF is needed, however long-term in-field studies will be required to show efficacy.

\section{Issues of treatment and prophylaxis}

To date only ribavirin, a broad anti-RNA virus inhibitor, demonstrates in vitro activity against CCHFV either in cell culture [33,34], or in mice models [35,36]. In the historical study conducted by Mardani et al. in Iran during 19992001 , the case fatality rate was $11.6 \%$ (8 of 69 patients) in the group treated with oral ribavirin compared with $58.3 \%$ (7 of 12 patients) in the untreated group, which corresponded to $80 \%$ efficacy $(P<0.001)$ [37]. This study constituted the basis for the World Health Organization (WHO) recommendations for treating CCHF patients with ribavirin. Promising results were also reported by others, and were mainly associated with early treatment [38-40]. However, the use of ribavirin for CCHF treatment remains an issue of controversy since no difference in case fatality rates was found in other studies [41-43], including the only randomized controlled trial published on this topic so far $(6.3 \%$ among 64 ribavirin-treated patients versus $5.6 \%$ among 72 untreated patients; $P=0.86$ ) [42]. Almost all data about ribavirin efficacy are limited to small observational studies and case series, and questions about methodological issues have been raised (for example no control for disease severity or day of initiation of treatment) [17]. In a recent meta-analysis of 21 studies assessing the efficacy of ribavirin on CCHF outcome, the authors concluded that current evidence is insufficient to provide a clear answer [44]. Currently, ribavirin is used in most endemic countries [17], and ethical issues about using a placebo-control group have been raised. Given the high fatality rates associated with CCHF, a well-designed multi-center, randomized controlled trial taking into account severity criteria is urgently needed in order to provide evidence-based data about ribavirin efficacy.

Recombinant and natural interferons- $\alpha$ exhibit activity against CCHFV in vitro, and might prove a promising treatment approach in the very early course of illness or as post-exposure prophylaxis, however no human studies have been conducted yet [45]. The MxA protein, an interferon-induced protein of the superfamily of large GTPases, is a key component in the interferon-induced inhibition of replication of several viruses, including CCHFV [46]. There are data suggesting that CCHFV possesses mechanisms to defeat the interferon-induced defense mechanisms by delaying IFN secretion for 48 hours post-infection [47]. This may allow the rapid progression of illness rendering the infection almost IFNinsensitive, a phenomenon that may be linked to its pathogenicity [47]. Specific laboratory findings may serve as prognostic factors for severe disease (for example severe thrombocytopenia, elevated transaminases, prolonged aPTT (activated partial thromboplastin time), decreased fibrinogen) with viral load and levels of specific cytokines playing an important factor affecting the course and the outcome of the disease [24,45,48-51]. These factors may be useful as criteria for the construction of an algorithm about whether and when antiviral medications should be given.

\section{Conclusions}

$\mathrm{CCHF}$ is a disease of public health importance with a high fatality rate that has risen in incidence and displayed geographical spread over the past decade. However, to date, the driving forces behind this spread and increase in incidence remain unclear. Given this, it would be worth identifying areas at risk for CCHF and enhance surveillance. Development of new therapies and an effective and safe vaccine against CCHF would also contribute to keep CCHF under control.

\section{Funding}

No funds were received.

\section{Abbreviations}

CCHF: Crimean-Congo hemorrhagic fever; CCHFV: Crimean-Congo hemorrhagic fever virus; IFN: interferon. 


\section{Author details}

'Department for Interventions in Health-Care Facilities, Hellenic Center for Disease Control and Prevention, 3-5 Agrafon Street, Athens, 15123 Greece. ${ }^{2}$ Department of Microbiology, Medical School, Aristotle University of Thessaloniki, Thessaloniki, Greece.

\section{Authors' contributions}

HCM conceived the review and designed the manuscript. Both authors contributed in the interpretation of literature and writing, and approved the final version.

\section{Competing interests}

The authors declare that they have no competing interests.

Received: 20 May 2011 Accepted: 8 December 2011

Published: 8 December 2011

\section{References}

1. Vorou R, Pierroutsakos IN, Maltezou HC: Crimean-Congo hemorrhagic fever. Curr Opin Infect Dis 2007, 20:495-500.

2. Hoogstraal $\mathrm{H}$ : The epidemiology of tick-borne Crimean-Congo hemorrhagic fever in Asia, Europe, and Africa. J Med Entomol 1979, 15:307-417.

3. Heyman P, Cochez C, Hofhuis A, van der Giessen J, Sprong H, Porter SR, Losson B, Saegerman C, Donoso-Mantke O, Niedrig M, Papa A: A clear and present danger: tick-borne diseases in Europe. Expert Rev Anti Infect Ther 2010, 8:33-50.

4. Casals J: Antigenic similarity between the virus causing Crimean hemorrhagic fever and Congo virus. Proc Soc Exp Biol Med 1969, 131:233-236.

5. Leblebicioglu H: Crimean-Congo haemorrhagic fever in Eurasia. Int $\mathrm{J}$ Antimicrob Agents 2010, 36(Suppl):S43-46.

6. Wölfel R, Paweska JT, Petersen N, Grobbelaar AA, Leman PA, Hewson R, Georges-Courbot MC, Papa A, Heiser V, Panning M, Günther S, Drosten C: Low-density macroarray for rapid detection and identification of Crimean-Congo hemorrhagic fever virus. J Clin Microbiol 2009, 47:1025-1030.

7. Maltezou HC, Maltezos E, Papa A: Contact tracing and serosurvey among healthcare workers exposed to Crimean-Congo hemorrhagic fever in Greece. Scand J Infect Dis 2009, 41:877-880.

8. Aradaib IE, Erickson BR, Mustafa ME, Khristova ML, Saeed NS, Elageb RM, Nichol ST: Nosocomial outbreak of Crimean-Congo hemorrhagic fever, Sudan. Emerg Infect Dis 2010, 16:837-839.

9. Nabeth P, Cheikh DO, Lo B, Faye O, Vall IO, Niang M, Wague B, Diop D, Diallo M, Diallo B, Diop OM, Simon F: Crimean-Congo hemorrhagic fever, Mauritania. Emerg Infect Dis 2004, 10:2143-2149.

10. Athar MN, Baqai HZ, Ahmad M, Khalid MA, Bashir N, Ahmad AM, Balouch AH, Bashir K: Short report: Crimean-Congo haemorrhagic fever outbreak in Rawalpindi, Pakistan, February 2002. Am J Trop Med Hyg 2003, 69:284-287.

11. Sidwell RW, Smee DF: Viruses of the Bunya- and Togaviridae families: potential as bioterrorism agents and means of control. Antiviral Res 2003, 57:101-111.

12. Maltezou HC, Papa A: Crimean-Congo hemorrhagic fever: risk for emergence of new endemic foci in Europe? Travel Me Infect Dis 2010, 8:139-143

13. Chinikar S, Ghiasi SM, Hewson R, Moradi M, Haeri A: Crimean-Congo hemorrhagic fever in Iran and neighboring countries. J Clin Virol 2010, 47:110-114.

14. World Health Organization: Crimean-Congo haemorrhagic fever number of cases, European Union, and Central Asia Republics and Kazakhstan. [http://data.euro.who.int/cisid/?TablD=265271], last accessed: May 14, 2011 .

15. Zakhashivilli, Tsertsvadze N, Chikviladze T, Jghenti E, Bekaia M, Kuchuloria T, Hepburn MJ, Imnadze P, Nanuashvili A: Crimean-Congo hemorrhagic ever in man, Republic of Georgia, 2009. Emerg Infect Dis 2010, 16:1326-1328.

16. Papa A, Tzalla E, Maltezou HC: Crimean-Congo hemorrhagic fever virus, Northestern Greece. Emerg Infect Dis 2011, 17:141-143.

17. Maltezon HC, Andonova L, Andraghetti R, Bouloy M, Ergonul O, Jongejan F, Kalvatchev N, Nichol S, Niedrig M, Platonov A, Thomson G, Leitmeyer K, Zeller $\mathrm{H}$ : Crimean-Congo hemorrhagic fever in Europe: current situation calls for preparedness. Eur Surveill 2010, 15:19504.
18. Smirnova SE: Circulation of Crimean-Congo hemorrhagic fever virus in the Stavropol territory in the seasons of 1999-2000. Zh Mikrobiol Epidemiol Immunobiol 2005, 3:49-53, in Russian.

19. Yilmaz GR, Buzgan T, Irmak H, Safran A, Uzun R, Cevik MA, Torunoglu MA: The epidemiology of Crimean-Congo hemorrhagic fever in Turkey, 20022007. Int J Infect Dis 2009, 13:380-386.

20. Gunes T, Engin A, Poyraz O, Elaldi N, Kaya S, Dokmetas I, Bakir M, Cinar Z: Crimean-Congo hemorrhagic fever virus in high-risk population, Turkey. Emerg Infect Dis 2009, 15:461-464.

21. Ertugrul B, Uyar Y, Yavas K, Turan C, Oncu S, Saylak O, Carhan A, Ozturk B, Erol N, Sakarya S: An outbreak of Crimean-Congo hemorrhagic fever in western Anatolia, Turkey. Int I Infect Dis 2009, 13:e431-436.

22. Randolph SE, Rogers DJ: Ecology of tick-borne disease and the role of climate. In Crimean-Congo Hemorrhagic Fever. A Global Perspective. Edited by: Ergonul O, Whitehouse CA. Dordrecht: Springer; 2007:167-186.

23. Randolph SE, Rogers DJ: The arrival, establishment and spread of exotic diseases: patterns and predictions. Nat Rev Microbiol 2010, 8:361-371.

24. Ergonul O: Crimean-Congo haemorrhagic fever. Lancet Infect Dis 2006, 6:203-214.

25. Filipe $A R$, Calisher $\mathrm{CH}$, Lazuick J: Antibodies to Congo-Crimean haemorrhagic fever, Dhori, Thogoto and Bhanja viruses in southern Portugal. Acta Virol 1985, 29:324-328.

26. Charrel RN, Attoui H, Butenko AM, Clegg JC, Deubel V, Frolova TV, Gould EA, Gritsun TS, Heinz FX, Labuda M, Lashkevich VA, Loktev V, Lundkvist A, Lvov DV, Mandl CW, Niedrig M, Papa A, Petrov VS, Plyusnin A, Randolph S, Süss J, Zlobin VI, de Lamballerie X: Tick-borne virus diseases of human interest in Europe. Clin Microbiol Infect 2004, 10:1040-1055.

27. Papa A, Dalla V, Papadimitriou E, Kartalis GN, Antoniadis A: Emergence of Crimean-Congo haemorrhagic fever in Greece. Clin Microbiol Infect 2010, 16:843-847.

28. Aradaib IE, Erickson BR, Karsany MS, Khristova ML, Elageb RM, Mohamed ME, Nichol ST: Multiple Crimean-Congo hemorrhagic fever virus strains are associated with disease outbreaks in Sudan, 2008-2009. PLoS Negl Trop Dis 2011, 5:e1159.

29. Estrada-Pena A, Venzal JM: Climate niches of tick species in the Mediterranean region: modeling of occurrence data, distributional constraints, and impact of climate change. J Med Entomol 2007, 33:1130-1138.

30. Keshtkar-Jahromi M, Kuhn JH, Christova I, Bradfute SB, Jahrling PB, Bavari S: Crimean-Congo hemorrhagic fever: current and future prospects of vaccines and therapies. Antiviral Res 2011, 90:85-92.

31. Maltezou HC, Papa A, Tsiodras S, Dalla V, Maltezos E, Antoniadis A: Crimean-Congo hemorrhagic fever in Greece: a public health perspective. Int J Infect Dis 2010, 13:713-716.

32. Papa A, Papadimitriou E, Christova I: The Bulgarian vaccine CrimeanCongo haemorrhagic fever virus strain. Scand J Infect Dis 2011, 43:225-229.

33. Watts DM, Ussery MA, Nash D, Peters CJ: Inhibition of Crimean-Congo hemorrhagic fever viral infectivity yields in vitro by ribavirin. Am J Trop Med Hyg 1989, 41:581-585.

34. Paragas J, Whitehouse CA, Endy TP, Bray M: A simple assay for determining antiviral activity against Crimean-Congo hemorrhagic fever virus. Antiviral Res 2004, 62:21-25.

35. Tignor GH, Hanham CA: Ribavirin efficacy in an in vitro model of Crimean-Congo hemorrhagic fever virus (CCHF) infection. Antiviral Res 1993, 22:309-325.

36. Bente DA, Alimonti JB, Shieh WJ, Camus G, Stroher U, Zaki S, Jones SM: Pathogenesis and immune response of Crimean-Congo hemorrhagic fever virus in a STAT-1 knockout mouse model. J Virol 2010, 84:11089-11100.

37. Mardani M, Jahromi MK, Naeni KH, Zeinali M: The efficacy of oral ribavirin in the treatment of Crimean-Congo hemorrhagic fever. Clin Infect Dis 2003, 36:1613-1618.

38. Fisgin NT, Ergonul O, Doganci L, Tulek N: The role of ribavirin in the therapy of Crimean-Congo hemorrhagic fever: early use is promising. Eur J Clin Microbiol Infect Dis 2009, 28:929-933.

39. Izadi S, Salehi M: Evaluation of the efficacy of ribavirin therapy on survival of Crimean-Congo hemorrhagic fever patients: a case-control study. Jpn J Infect Dis 2009, 62:11-15.

40. Ergonul O, Celikbas A, Dokuzoguz B, Eren S, Baykam N, Esener H: Characteristics of patients with Crimean-Congo hemorrhagic fever in a 
recent outbreak in Turkey and impact of oral ribavirin therapy. Clin Infect Dis 2004, 39:284-287.

41. Cevik MA, Elardi N, Akinci E, Onguru P, Erbay A, Buzgan T, Uzun R, Kubar A, Bodur $\mathrm{H}$ : A preliminary study to evaluate the effect of intravenous ribavirin treatment on survival rates in Crimean-Congo hemorrhagic fever. J Infect 2008, 57:350-359.

42. Koksal I, Yilmaz G, Aksoy F, Aydin H, Yavuz I, Iskender S, Akcay K, Erensoy S, Caylan R, Aydin K: The efficacy of ribavirin in the treatment of CrimeanCongo hemorrhagic fever in Eastern Black Sea region in Turkey. J Clin Virol 2010, 47:65-68.

43. Bodur H, Erbay A, Akinci E, Onguru P, Bayazit N, Eren SS, Kubar A: Effect of oral ribavirin treatment on the viral load and disease progression in Crimean-Congo hemorrhagic fever. Int I Infect Dis 2011, 15:e44-e47.

44. Soares-Weiser K, Thomas S, Thomson G, Garner P: Ribavirin for CrimeanCongo hemorrhagic fever: systemic review and meta-analysis. BMC Infect Dis 2010, 10:207.

45. Karlberg H, Lindegren G, Mirazimi A: Comparison of antiviral activity of recombinant and natural interferons against Crimean-Congo hemorrhagic fever virus. Open Virol J 2010, 4:38-41.

46. Andersson I, Bladh L, Mousavi-Jazi M, Magnusson KE, Lundkvist A, Haller O, Mirazimi A: Human MxA protein inhibits the replication of CrimeanCongo hemorrhagic fever virus. J Virol 2004, 78:4323-4329.

47. Andersson I, Karlberg H, Mousavi-Jazi M, Martinez-Sobrido L, Weber F, Mirazimi A: Crimean-Congo hemorrhagic fever virus delays activation of the innate immune response. J Med Virol 2008, 80:1397-1404.

48. Saksida A, Duh D, Wraber B, Dedushaj I, Ahmeti S, Avsic-Zupanc T: Interacting roles of immune mechanisms and viral load in the pathogenesis of Crimean-Congo hemorrhagic fever. Clin Vaccine Immunol 2010, 17:1086-1093.

49. Papa A, Drosten C, Bino S, Papadimitriou E, Panning M, Velo E, Kota M, Harxhi A, Antoniadis A: Viral load and Crimean-Congo hemorrhagic fever. Emerg Infect Dis 2007, 13:805-806.

50. Cevik MA, Erbay A, Bodur H, Eren SS, Akinci E, Sener K, Ongürü P, Kubar A: Viral load as a predictor of outcome in Crimean-Congo hemorrhagic fever. Clin Infect Dis 2007, 45:e96-100.

51. Papa A, Bino S, Velo E, Harxhi A, Kota M, Antoniadis A: Cytokine levels in Crimean-Congo hemorrhagic fever. J Clin Virol 2006, 36:272-276.

\section{Pre-publication history}

The pre-publication history for this paper can be accessed here: http://www.biomedcentral.com/1741-7015/9/131/prepub

doi:10.1186/1741-7015-9-131

Cite this article as: Maltezou and Papa: Crimean-Congo hemorrhagic fever: epidemiological trends and controversies in treatment. BMC Medicine 2011 9:131.

\section{Submit your next manuscript to BioMed Central and take full advantage of:}

- Convenient online submission

- Thorough peer review

- No space constraints or color figure charges

- Immediate publication on acceptance

- Inclusion in PubMed, CAS, Scopus and Google Scholar

- Research which is freely available for redistribution 